\title{
Reductive Polycondensation of Dialdehydes with Diamines Using Sodium Triacetoxyborohydride
}

\author{
Tatsuaki SaKano, Yoritatsu KaWaI, Takaki Kanbara, ${ }^{\dagger}$ \\ and Kiyoshi Hasegawa \\ Department of Chemical and Biochemical Engineering, Faculty of Engineering, \\ Toyama University, 3190 Gofuku, Toyama 930-8555, Japan
}

(Received March 27, 1998)

\begin{abstract}
KEY WORDS Polycondensation/Reductive Amination / Polyamines / Dialdehyde / Secondary Diamine / Sodium Triacetoxyborohydride /
\end{abstract}

Condensation-type polyamines are generally prepared by dehydrohalogenation condensation of primary or secondary diamines with dihalogenated compounds, ${ }^{1}$ however, the reaction often requires severe reaction conditions or activated substrates. In contrast, there have been few reports on preparation of polyamines using dialdehydes and diamines. ${ }^{2}$ For example, an indirect synthesis of polyamines has been achieved by the polycondensation of aromatic or aliphatic diamines with terephthalaldehyde giving polyazomethines followed by hydrogenation with a reducing agent.

On the other hand, the reactions of aldehydes or ketones with amines in the presence of reducing agents, known as reductive aminations, are among the most useful and important tools in the synthesis of different kinds of amines. ${ }^{3}$ Recently, Abdel-Magid et al. have reported that sodium triacetoxyborohydride $(\mathrm{NaBH}-$ $\left.(\mathrm{OAc})_{3}\right)$ is an effective reducing agent for the direct reductive aminations of aldehydes with amines under mild conditions. ${ }^{3 \mathrm{~d}}$ The reductive amination of dialdehydes with diamines would afford polyamines through an one-pot polycondensation according to eq 1 .

$$
\begin{aligned}
& n \mathrm{OHC}-\mathrm{R}-\mathrm{CHO}+n \mathrm{R}^{\prime \prime}-\mathrm{N}-\mathrm{R}^{\prime}-\mathrm{N}-\mathrm{R}^{\prime \prime} \\
& \mathrm{H} \quad \mathrm{H}
\end{aligned}
$$

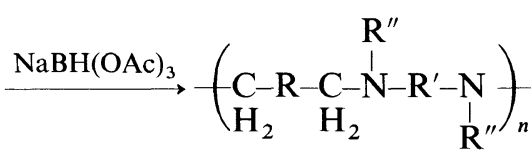

Reductive homo- and co-polymerizations have recently attracted attention in polymer chemistry, and various polyethers, ${ }^{4}$ poly(oxamide)s, ${ }^{5}$ and polypinacols ${ }^{6}$ have been prepared. We here report the results of the reductive polycondensation of dialdehydes with diamines.

\section{EXPERIMENTAL}

IR and NMR spectra were recorded on a JASCO FT/IR-230 spectrometer and a JEOL JNM-A400 NMR spectrometer, respectively. Weight-average molecular weights $\left(M_{w}\right)$ of the polymers were measured by the light scattering method with a Photal DLS-7000DH/DL light scattering spectrophotometer. Elemental analyses were carried out with a Yanaco CHN Corder MT-5.

Ferrocene-1,1'-dicarbaldehyde, ${ }^{7}$ bis(4-formylphenyl)

\footnotetext{
$\uparrow^{\dagger}$ To whom correspondence should be addressed.
}

succinate, ${ }^{4 \mathrm{a}}$ and 2,5-didodecyloxyterephthalaldehyde ${ }^{8}$ were prepared according to the literature procedures. The other monomers have been purified by recrystallization prior to use.

A typical polymerization procedure is as follows. A mixture of isophthalaldehyde (IPA) $(268 \mathrm{mg}, 2 \mathrm{mmol})$ and 4,4'-trimethylenedipiperidine (TMDP) (421 mg, 2 mmol) was dissolved in 1,2-dichloroethane (DCE) $(20$ $\mathrm{ml}) . \mathrm{NaBH}(\mathrm{OAc})_{3}(1.272 \mathrm{~g}, 6 \mathrm{mmol})$ and $\mathrm{LiCl}(212 \mathrm{mg}$, $5 \mathrm{mmol})$ were added to the solution. The reaction mixture was stirred at $25^{\circ} \mathrm{C}$ for $48 \mathrm{~h}$ under nitrogen. The reaction mixture was quenched by adding a $\mathrm{NaOH}$ aqueous solution $(1 \mathrm{M}, 100 \mathrm{ml})$, and the product was extracted with $\mathrm{CHCl}_{3}$. The organic fraction was concentrated, and reprecipitation from $\mathrm{CHCl}_{3} /$ methanol and $\mathrm{CHCl}_{3}$ / ether gave a white powder of poly $\left[\left(4,4^{\prime}\right.\right.$-trimethylenedipiperidine-1,1'-diyl)methylene-1,3-phenylenemethylene] (poly-1) (318 mg, 51\% yield). Anal. Found: C, 80.3\%; $\mathrm{H}, 10.3 \%$; N, 9.0\%. Calcd for $\left(\mathrm{C}_{21} \mathrm{H}_{32} \mathrm{~N}_{2}\right)_{n}$ : C, 80.7\%; $\mathrm{H}, 10.3 \% ; \mathrm{N}, 9.0 \%$. Other polyamines were prepared analogously. The $\mathrm{CHCl}_{3}$ insoluble fraction of the polymers was purified by washing thoroughly with methanol and ether.

\section{RESULTS AND DISCUSSION}

When the reaction of IPA with TMDP was carried out without $\mathrm{NaBH}(\mathrm{OAc})_{3}$, only a trace of oligomeric product was obtained. On the other hand, the reactions using $\mathrm{NaBH}(\mathrm{OAc})_{3}$ for $24-48 \mathrm{~h}$ afforded poly-1 in moderate yields. Table I summarizes the results of the reductive polycondensation of IPA with TMDP under various conditions. The reductive polycondensation proceeded smoothly in the presence of small excess amount of $\mathrm{NaBH}(\mathrm{OAc})_{3}$ (3 equiv. for monomer) at room temperature. The light scattering measurement of poly-1 with an inherent viscosity $\left(\eta_{\text {inh }}\right)$ of $0.21 \mathrm{~g} \mathrm{dl}^{-1}$ (Table I, Run 6) showed $M_{w}$ of 7200 . An addition of large excess amount of $\mathrm{NaBH}(\mathrm{OAc})_{3}$ decreased polymer yields and $\eta_{\text {inh }}$ values. Aldehyde group could be reduced with $\mathrm{NaBH}(\mathrm{OAc})_{3}$ to the corresponding alcohol, ${ }^{3 \mathrm{~d}}$ and the undesirable reduction might prevent propagation of the polymer chain and result in lower yields of the polymer. An addition of $\mathrm{LiCl}$ gave the product with somewhat higher $\eta_{\text {inh }}$. The presence of $\mathrm{LiCl}$ is considered to cleave the hydrogen bond of the intermediate hydroxylamine 
Table I. Reductive polycondensation of isophthalaldehyde with $4,4^{\prime}$-trimethylenedipiperidine under various conditions ${ }^{\mathbf{a}}$

\begin{tabular}{|c|c|c|c|c|c|c|}
\hline \multirow{2}{*}{ Run } & \multirow{2}{*}{$\begin{array}{c}\mathrm{NaBH}(\mathrm{OAc})_{3} / \\
\text { Monomer }\end{array}$} & \multirow{2}{*}{ Solvent } & Temp & \multirow{2}{*}{$\begin{array}{c}\mathrm{LiCl} / \\
\text { Monomer }\end{array}$} & \multirow{2}{*}{$\frac{\text { Yield }^{\mathbf{b}}}{\%}$} & \multirow{2}{*}{$\frac{\eta_{\text {inh }}{ }^{\mathrm{c}}}{\mathrm{gdL}^{-1}}$} \\
\hline & & & ${ }^{\circ} \mathrm{C}$ & & & \\
\hline 1 & 0 & $\mathrm{DCE}^{\mathrm{d}}$ & 25 & - & Trace & - \\
\hline 2 & 2 & $\mathrm{DCE}$ & 25 & - & 6 & 0.07 \\
\hline 3 & 3 & DCE & 25 & - & 56 & 0.18 \\
\hline 4 & 4 & DCE & 25 & - & 47 & 0.13 \\
\hline 6 & 3 & DCE & 25 & 2.5 & 51 & 0.21 \\
\hline 7 & 3 & DCE & 70 & 2.5 & 47 & 0.18 \\
\hline 8 & 3 & DCE & 5 & 2.5 & 28 & 0.19 \\
\hline 9 & 3 & THF & 25 & 2.5 & 58 & 0.20 \\
\hline 10 & 3 & Dioxane & 25 & 2.5 & 44 & 0.20 \\
\hline $11^{\mathrm{e}}$ & 3 & DCE & 25 & - & 50 & 0.19 \\
\hline
\end{tabular}

${ }^{a}$ Stirring for $48 \mathrm{~h}$ under $\mathrm{N}_{2}$. ${ }^{\mathrm{b}}$ Insoluble fraction in ether and methanol. ${ }^{\mathrm{c}} \mathrm{Measured}$ at a concentration of $1.0 \mathrm{~g} \mathrm{dL}^{-1}$ in $\mathrm{CHCl}_{3}$ at $30^{\circ} \mathrm{C}_{\text {. }}$ d 1,2-Dichloroethane. ${ }^{\mathrm{e}}$ Acetic acid (1.0 equiv. for monomer) was added.
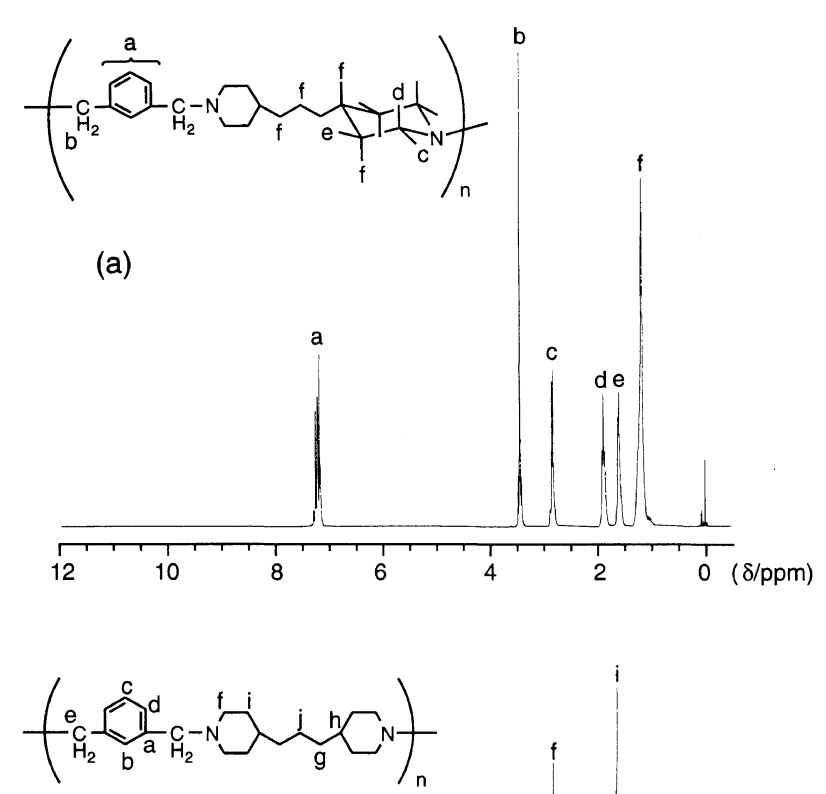

(b)

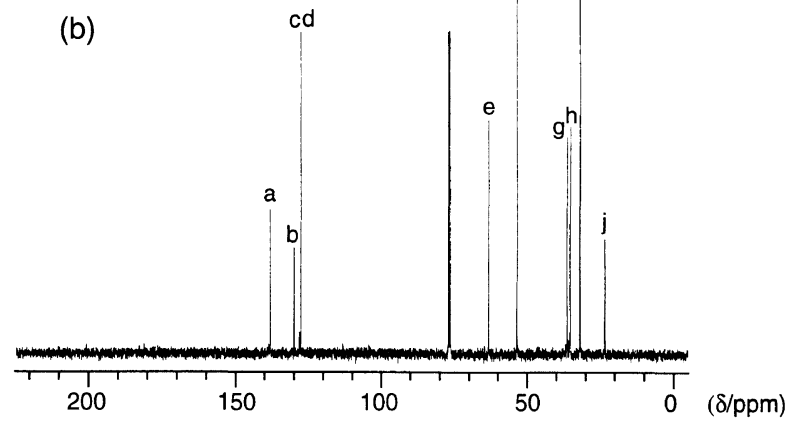

Figure 1. ${ }^{1} \mathrm{H}$ (a) and ${ }^{13} \mathrm{C}$ (b) NMR spectra of poly-1 in $\mathrm{CDCl}_{3}$.

and facilitate the formation of the iminium intermediate. ${ }^{9}$ An addition of acetic acid ${ }^{3 d}$ was not effective for the reaction. The reactions at higher temperature $\left(70^{\circ} \mathrm{C}\right)$ and lower temperature $\left(5^{\circ} \mathrm{C}\right)$ decreased yields and $\eta_{\text {inh }}$ of the products. Use of tetrahydrofuran (THF) and 1,4-dioxane as solvents also gave the polymer in moderate yields.

$\mathrm{Ti}(\mathrm{OiPr})_{4} / \mathrm{NaBH}_{4}{ }^{3 \mathrm{~b}} \mathrm{Cl}_{3} \mathrm{SiH}-\mathrm{DMF},{ }^{3 \mathrm{c}}$ and boranepyridine complex ${ }^{3 e, f}$ have also been presented as reducing agents for the reductive amination of aldehydes or ketones with amines. However, in the present study, the polycondensation reactions using the reducing agents resulted in little or no product formation.
Figure 1 shows the ${ }^{1} \mathrm{H}$ and ${ }^{13} \mathrm{C}$ NMR spectra of poly-1 (Table I, Run 6) in $\mathrm{CDCl}_{3}$. The peaks were assigned by comparison of the peak positions of poly-1 with those of monomers. The ${ }^{1} \mathrm{H}$ and ${ }^{13} \mathrm{C}$ NMR spectra were also confirmed by ${ }^{1} \mathrm{H}-{ }^{1} \mathrm{H}$ COSY and DEPT spectra, respectively. In Figure 1(a), the ratios of the peak area agree with the suggested assignment. A peak attributable to methylene protons formed by the reductive amination of aldehyde is observed at $\delta 3.5 \mathrm{ppm}$, and no peak assignable to the aldehyde end group ( $\delta 10.1 \mathrm{ppm}$ for IPA) is observed. The ${ }^{13} \mathrm{C}$ NMR spectrum of poly-1 (Figure 1(b)) shows 10 peaks, and a peak assignable to methylene group formed by the reductive amination is observed at $\delta 63.5 \mathrm{ppm}$. IR spectrum of poly-1 shows a disappearance of the bands due to $v(\mathrm{C}=\mathrm{O})\left(1694 \mathrm{~cm}^{-1}\right.$ for IPA) and $v(\mathrm{~N}-\mathrm{H})\left(3190 \mathrm{~cm}^{-1}\right.$ for TMDP $)$.

Table II summarizes the results of the reductive polycondensation of various dialdehydes with diamines under the same conditions as that of Run 6 in Table I. The structures of the polymers were confirmed by IR and NMR spectroscopy. Elemental analysis data of the polymers are reasonable for the calculated values for the corresponding structures. The polyamines (Runs 7, 8 in Table II) contain a $\mathrm{CHCl}_{3}$ insoluble fraction with high molecular weights, however, it is soluble in acidic solvents such as formic acid and acetic acid. IR spectrum of the $\mathrm{CHCl}_{3}$ insoluble fraction is identical to those of the $\mathrm{CHCl}_{3}$ soluble fraction.

As shown in Table II, electronic properties of aromatic dialdehydes may affect the reductive polycondensation. The reactions using electron-rich aromatic dialdehydes such as 2,5-thiophenedicarbaldehyde, ferrocene-1,1'dicarbaldehyde, and 2,5-didodecyloxyterephthalaldehyde afforded polymers in moderate to good yields (Runs 2, 4, and 5). In contrast, use of 2,6-pyridinedicarbaldehyde and bis(4-formylphenyl) succinate, which are electron-poor aromatic dialdehydes, provided polyamines in lower yields (Runs 3 and 6). The electron withdrawing effect of the pyridine ring and acyloxy substituent would inhibit formation of the iminium intermediate. ${ }^{3 \mathrm{f}}$ The reactions using cyclic secondary diamines such as TMDP and piperazine gave the products in moderate to good yields, whereas employing less nucleophilic acyclic secondary diamines and aromatic secondary diamines such as $N, N^{\prime}$-diethylethylenediamine 
Table II. Reductive polycondensation of various aryl dialdehydes and diamines ${ }^{\mathrm{a}}$

\begin{tabular}{|c|c|c|c|c|c|}
\hline Run & Dialdehydes & Diamines & $\frac{\text { Yield }^{\mathrm{b}}}{\%}$ & $\frac{\eta_{\mathrm{inh}}{ }^{\mathrm{c}}}{\mathrm{gdL}^{-1}}$ & $\begin{array}{c}M_{w}{ }^{\mathrm{d}} \\
\times 10^{-3}\end{array}$ \\
\hline 1 & & & 51 & 0.21 & 7.2 \\
\hline 2 & & & 65 & 0.20 & 7.8 \\
\hline 3 & & & 45 & 0.16 & $-^{e}$ \\
\hline 4 & & & 55 & 0.26 & 10.7 \\
\hline 5 & & & 63 & 0.19 & 7.0 \\
\hline 6 & & & 28 & 0.10 & \\
\hline 7 & & & $40(2$ & & \\
\hline 8 & & & 79 (7 & & \\
\hline
\end{tabular}

${ }^{\text {a }}$ The polycondensation of dialdehydes $(2 \mathrm{mmol})$ and diamines $(2 \mathrm{mmol})$ was carried out in the presence of $\mathrm{NaBH}(\mathrm{OAc})_{3}(6 \mathrm{mmol})$ and $\mathrm{LiCl}$ $(5 \mathrm{mmol})$ in DCE $\left(20 \mathrm{~cm}^{3}\right)$ at $25^{\circ} \mathrm{C}$ for $48 \mathrm{~h}$. ${ }^{b}$ Total yield; the number in the parentheses is the yield of $\mathrm{CHCl}_{3}$ insoluble fraction. ${ }^{\mathrm{c}}$ Measured at a concentration of $1.0 \mathrm{~g} \mathrm{dL}^{-1}$ in $\mathrm{CHCl}_{3}$ at $30^{\circ} \mathrm{C}$. ${ }^{\mathrm{d}}$ Determined by light scattering method. ${ }^{\mathrm{e}} \mathrm{The} \mathrm{Zimm}$ plot was obscure presumably due to low molecular weight.

and $N, N^{\prime}$-diphenyl-p-phenylenediamine failed to promote the polycondensation.

In relation to the polycondensation of dialdehydes with secondary diamines, the polycondensation of IPA with primary diamines such as $m$-phenylenediamine also provided the polymer in good yield (Table II, Run 8). However, the obtained polymer was insoluble in common organic solvents, presumably due to partially cross-linked structures.

As described above, several new polyamines are easily obtained by the reductive polycondensation using $\mathrm{NaBH}(\mathrm{OAc})_{3}$ under mild conditions. Although yields and molecular weights of the polymers are not high in the present study, the polycondensation could provide a variety of polyamines by changing the structure of dialdehydes and diamines. Further studies for obtaining the appropriate conditions for the polycondensation as well as preparation of other polyamines are now in progress.

Acknowledgments. The authors are grateful to Prof. H. Kitano of our department for the light scattering measurement. This work has been financially supported from Mitsubishi Chemical Foundation.

\section{REFERENCES}

1. D. Brown, J. Polym. Sci., Polym. Lett., 6, 415 (1968); Y. Imai, M. Ueda, and K. Otaira, J. Polym. Sci., Polym. Chem. Ed., 15, 1457 (1977); M. Padmanaban, Y. Oishi, M. Kakimoto, and Y. Imai, Polym. J., 21, 577 (1989); Y. Yuki, H. Kunisada, K. Iida, and S. Kondo, Polym. J., 28, 553 (1996); J. F. Klebe, J. Polym. Sci., A, 2, 2673 (1964).

2. E. Dyer and C. C. Anderson, J. Polym. Sci., Part A-1, 5, 1659 (1967).

3. a) C. F. Lane, Synthesis, 135 (1975); b) S. Bhattacharyya, A. Chatterjee, and J. S. Williamson, Synlett, 1075 (1995); c) S. Kobayashi, M. Yasuda, and I. Wachiya, Chem. Lett., 407 (1996); d) A. F. Abdel-Magid, K. G. Carson, B. D. Harris, C. A. Maryanoff, and R. D. Shah, J. Org. Chem., 61, 3849 (1996); e) A. Peltet and R. M. Rosser, J. Chem. Soc., Perkin. Trans., 1, 719 (1984); f) A. E. Moormann, Syn. Commun., 23, 789 (1993).

4. a) T. Yokozawa and F. Nakamura, Macromolecules, 28, 4668 (1995); b) T. Yokozawa and K. Takenoya, Macromolecules, 29, 497 (1996).

5. J. Wang, R. Nomura, and T. Endo, J. Polym. Sci., Part A, Polym. Chem., 33, 869 and 2901 (1995).

6. N. E. Brandukova, Y. S. Vygodskii, and S. V. Vinogradova, Polym. Sci., A, 36, 6 (1994); V. U. Wege and A. Grieiner, Acta. Polym., 46, 391 and 396 (1995).

7. G. G. A. Balavoine, G. Doisneau, and T. Fillebeen-Kham, $J$. Organomet. Chem., 412, 381 (1991).

8. B. Wang and M. R. Wasielewski, J. Am. Chem. Soc., 119, 12 (1997).

9. P. W. Morgan, S. L. Kwolek, and T. C. Pletcher, Macromolecules, 20, 729 (1987). 